\title{
Effect of fluoride on the learning and memory ability of larvae of Zaprionus indianus
}

\author{
Diksha Mishra, Rishu Kumari, Smita Ranjan and Shahla Yasmin * ${ }^{*}$
}

\begin{abstract}
Background: Many pesticides contain fluoride that enters the food chain and affect the non-target organisms. Fluoride is a known neurotoxin and may cause neurobehavioral defects. A study was conducted to see the effect of fluoride on the learning and memory ability of larvae of Zaprionus indianus. The learning and memory ability of 2nd instar larvae of normal (control) and sodium fluoride (NaF)-treated Zaprionus indianus was compared.

Results: Sublethal concentration of $\mathrm{NaF}$ for $Z$. indianus was found to be $0.8 \mathrm{ppm}$. Olfactory assay results showed that the larvae of normal (control) Z. indianus had better learning and memory ability in comparison to NaF-treated larvae.

Conclusions: This study indicates that the insects exposed to pesticides containing fluoride may have difficulty in locating food sources and carrying out pollination.
\end{abstract}

Keywords: Zaprionus indianus, Sodium fluoride, Olfactory assay, 2nd instar larvae, Learning and memory

\section{Background}

Exposure to fluoride can occur through dietary intake, respiration, and water. Fluoride enters the environment through volcanic eruptions, rock dissolution, and numerous human activities (coal burning, ore processing, production and use of fertilizers, and industrial plants). Many pesticides, insecticides, and weedicides contain fluoride in high concentrations, and the overuse of such chemicals paves way for fluoride to enter the system of non-targeted organisms such as human beings and other animals and cause derogatory effects. Acute pesticide poisoning occurs frequently in children worldwide, and subclinical pesticide toxicity is also widespread (Grandjean \& Landrigan, 2014). Clinical data suggest that acute pesticide poisoning during childhood might lead to lasting neurobehavioral deficits (Kofman, Berger, Massarwa, Friedman, \& Jaffar, 2006; London et al., 2012). Thus, there is a need to study the neurotoxic effect of fluoride.

\footnotetext{
*Correspondence: shahla_apex@yahoo.co.in

Department of Zoology, Patna Women's College, Bailey Road, Patna, Bihar 800001, India
}

Fruit flies and mammals share many genes suggesting that the molecular mechanisms of behavioral plasticity might also be shared (Rubin et al. 2000). Short life span, large number of offspring produced, a well-known anatomy, and occurrence of a wide variety of mutants are convenient characteristics of fruit flies as a model organism (Jeibman and Paulus, 2009).

Olfaction in fruit fly is crucial for a variety of behaviors, including associative learning (Quinn et al., 1974, Tully and Quinn, 1985) courtship (Gailley et al. 1986), foraging (Shaver et al. 1998; Frye and Dickinson, 2004), and flight (Schneiderman and Trimarchi, 1995). Fruit flies can learn to associate olfactory or visual cues with rewarding or punishing reinforcement. Fruit fly memory persists for hours or days, depending on the training protocol. Multiple spaced training trials form long-term memory that can persist for days (Keene and Waddell, 2007). Fruit fly larvae can be used as model organisms to study the neurotoxic effect of fluoride.

Zaprionus indianus (Gupta, 1970) is an arthropod belonging to the fruit fly family Drosophilidae. Z. indianus

\section{Springer Open}

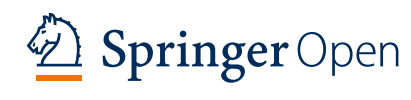

(c) The Author(s). 2020 Open Access This article is licensed under a Creative Commons Attribution 4.0 International License, which permits use, sharing, adaptation, distribution and reproduction in any medium or format, as long as you give appropriate credit to the original author(s) and the source, provide a link to the Creative Commons licence, and indicate if changes were made. The images or other third party material in this article are included in the article's Creative Commons licence, unless indicated otherwise in a credit line to the material. If material is not included in the article's Creative Commons licence and your intended use is not permitted by statutory regulation or exceeds the permitted use, you will need to obtain permission directly from the copyright holder. To view a copy of this licence, visit http://creativecommons.org/licenses/by/4.0/. 
Table 1 Olfactory Response Index (ORI) of 2nd instar larvae of Zaprionus indianus for different concentrations of iso-amyl acetate (IAA) and apple cider vinegar (ACV)

\begin{tabular}{llllll}
\hline $\begin{array}{l}\text { Different concentration } \\
\text { of IAA }\end{array}$ & $\begin{array}{l}\text { Olfactory Response } \\
\text { Index (ORI) }\end{array}$ & Mean \pm SE & Different concentration of ACV & Olfactory Response Index (ORI) & Mean \pm SE \\
\hline Distilled water (DW) & $0.00,0.04,0.00$ & $0.01 \pm 0.01$ & Distilled water (DW) & $0.00,-0.02,0.00$ & $-0.01 \pm 0.01$ \\
$10^{-1}$ & $0.03,-0.05,0.16$ & $0.05 \pm 0.06$ & $10^{-1}$ & $0.36,0.14,0.08$ & $0.19 \pm 0.09$ \\
$10^{-2}$ & $-0.19,-0.08,-0.21$ & $-0.16 \pm 0.04$ & $10^{-2}$ & $0.07,0.25,0.25$ & $0.19 \pm 0.06$ \\
$10^{-4}$ & $0.05,0.02,0.32$ & $0.13 \pm 0.09$ & $10^{-4}$ & $-0.20,0.03,0.06$ & $-0.04 \pm 0.08$ \\
\hline
\end{tabular}

is abundantly found around fruit trees such as guava and mango and may help the trees in carrying out the process of pollination. Due to this, $Z$. indianus is at a risk of being exposed to insecticides that contain fluoride that is a potential neurotoxin. This may result in the organism losing track of its trail, and if that happens, the fly will ultimately die because it will not be able to find its food, and the trees dependent on the fly for the dispersal of pollen may suffer too. A study on this aspect has not been conducted so far. This paper presents the effect of sublethal level of sodium fluoride $(\mathrm{NaF})$ on the learning and memory ability of 2nd instar larvae of $Z$. indianus (Gupta, 1970).

\section{Methods}

The assessment of memory ability of $Z$. indianus was done using its 2 nd instar larvae. $Z$. indianus flies were trapped using fruit baits and cultured in the laboratory on cornmeal medium. Single line culture of flies was maintained by transferring a gravid fly in separate cornmeal medium containing bottles. The larvae obtained were assessed for their learning and memory ability with the help of olfactory assay following Scherer, Stocker, and Bertram Gerber (2003). Four sets of $100 \mathrm{ml}$ cornmeal medium were prepared to be poured in sixteen glass bottles. Each set contained four bottles. Out of all the four sets, one set was used as control, and the rest three were experimental set up.

First, iso-amyl acetate (IAA) was used as attractant since Drosophila melanogaster is attracted towards it (Khurana and Siddiqui, 2013). But Z. indianus larvae did not show appreciable response towards IAA. Next, apple cider vinegar (ACV) was used as odourant to attract Zaprionus indianus larvae following Joshi, Biddinger, Demchak, and Deppen (2014). Olfaction assay was performed to determine the concentration at which larvae of $Z$. indianus was maximum attracted. Olfactory assay was performed with following concentrations $\mathrm{ACV}$, i.e., $10^{-1}, 10^{-2}$, and $10^{-4}$.

Thereafter, $1000 \mathrm{ppm} \mathrm{NaF}$ stock solution was prepared by adding $2.21 \mathrm{~g}$ of $\mathrm{NaF}$ into $1000 \mathrm{ml}$ distilled water. $\mathrm{NaF}$ of the concentrations $0.8 \mathrm{ppm}, 1.0 \mathrm{ppm}$, and 1.5 ppm was taken to treat the flies. Three sets of cornmeal medium were prepared. Each set contained four bottles.
The first set had $0.8 \mathrm{ppm} \mathrm{NaF}$, the second set had 1.0 ppm NaF, and the third set had $1.5 \mathrm{ppm} \mathrm{NaF}$ containing cornmeal medium. Zaprionus indianus flies from single line stock culture were transferred into each of these bottles such that each bottle contained at least one gravid fly.

\section{Olfactory assay}

Plain agar petri plates were taken. A filter paper was taken on which a circle and two vertical lines were drawn in the center, and two diametrically opposite points were marked close to the periphery of the petri plates and were termed as $C_{1}$ and $C_{2}$.

\section{Procedure for olfactory assay Control test}

Agar plate was divided into two halves, and one drop of distilled water was placed on each side with the help of a dropper. Sixty 2nd instar larvae were introduced at the center, covered with black box and left for $2 \mathrm{~min}$. After 2 min, larvae were counted on both sides $\left(C_{1}\right.$ and $\left.C_{2}\right)$, and Olfactory Response Index (ORI) was calculated.

\section{Experimental test}

$10^{-2}$ concentration of ACV was used as attractant on one side and distilled water on the other side of petri plate with plain agar. Same set of 2nd instar larvae was introduced at the center covered with black box and left

Table 2 Culture of flies in $0.8 \mathrm{ppm} \mathrm{NaF}$ in four different bottles

\begin{tabular}{lllll}
\hline Date & A & B & C & D \\
\hline 13.09 .18 & 5 flies & 5 flies & 2 flies & 5 flies \\
14.09 .18 & 5 flies + eggs & 5 flies + eggs & 2 flies + eggs & 4 flies + eggs \\
15.09 .18 & 5 flies + larvae & 4 flies + larvae & 2 flies + larvae & 4 flies + larvae \\
16.09 .18 & 5 flies + larvae & 4 flies + larvae & 2 flies + larvae & 4 flies + larvae \\
17.09 .18 & 5 flies + pupa & 4 flies + pupa & 2 flies + pupa & 4 flies + pupa \\
18.09 .18 & 5 flies + pupa & 3 flies + pupa & 2 flies + pupa & 4 flies + pupa \\
19.09 .18 & 5 flies + pupa & 3 flies + pupa & 2 flies + pupa & 4 flies + pupa \\
20.09 .18 & 20 flies & 3 flies + pupa & 7 flies & 10 flies \\
21.09 .18 & 20 flies & 10 flies & 7 flies & 10 flies \\
22.09 .18 & 20 flies & 10 flies & 7 flies & 10 flies \\
\hline
\end{tabular}


Table 3 Culture of flies in 1.0 ppm NaF in four different bottles

\begin{tabular}{lllll}
\hline Date & A & B & C & D \\
\hline 13.09 .18 & 5 flies & 5 flies & 5 flies & 3 flies \\
14.09 .18 & 5 flies & 5 flies + eggs & 4 flies + eggs & 3 flies \\
15.09 .18 & 5 flies & 4 flies + eggs & 3 flies + eggs & 2 flies \\
16.09 .18 & 4 flies & 4 flies, no larvae & 3 flies, no larvae & Dead flies \\
17.09 .18 & 4 flies & 3 flies, no larvae & 2 flies, no larvae & Dead flies \\
18.09 .18 & 2 flies & 3 flies, no larvae & Dead flies & Dead flies \\
19.09 .18 & 2 flies & Dead flies & Dead flies & Dead flies \\
\hline
\end{tabular}

for $2 \mathrm{~min}$. After $2 \mathrm{~min}$, larvae were counted on both sides, and ORI was calculated.

\author{
Formula for calculating ORI \\ ORI $=\mathrm{C}_{1}-\mathrm{C}_{2} / \mathrm{C}_{1}+\mathrm{C}_{2}$ \\ Here, \\ $\mathrm{C}_{1}=$ no. of larvae on side one $(\mathrm{ACV})$ \\ $C_{2}=$ no. of larvae on side second (distilled water)
}

\section{Avoidance test}

Next, agar plate was neatly cut into half, and half of it was removed and replaced with agar containing $20 \mathrm{mM}$ $\mathrm{NaCl}$. $\mathrm{NaCl}$ played the role of irritant. ACV was placed on the side containing $\mathrm{NaCl}$, and on the other side distilled water was put. Same set of larvae was introduced in the center, and assay was performed as during experimental test. ORI was calculated.

\section{Confirmatory test}

Next, same set of larvae was again placed on plain agar petri plate containing $\mathrm{ACV}$ on one side and distilled water on the other, and olfactory assay performed as during experimental test. ORI is calculated.

\section{Experimental set up}

Similarly, larvae treated with sublethal level of $\mathrm{NaF}$ were also introduced on plain agar petri plates and control test, experimental test, avoidance test, and confirmatory test were performed.

Table 4 Culture of flies in $1.5 \mathrm{ppm} \mathrm{NaF}$ in four different bottles

\begin{tabular}{lllll}
\hline Date & A & B & C & D \\
\hline 13.09 .18 & 3 flies & 4 flies & 6 flies & 4 flies \\
14.09 .18 & 3 flies + no eggs & Dead flies & 2 flies & 1 fly \\
15.09 .18 & 2 flies, no larvae & Dead flies & 2 flies & Dead flies \\
16.09 .18 & Dead flies & Dead flies & Dead flies & Dead flies \\
17.09 .18 & Dead flies & Dead flies & Dead flies & Dead flies \\
18.09 .18 & Dead flies & Dead flies & Dead flies & Dead flies \\
19.09 .18 & Dead flies & Dead flies & Dead flies & Dead flies \\
\hline
\end{tabular}

Table 5 Olfactory Response Index (ORI) for normal Z. indianus larvae

\begin{tabular}{lllll}
\hline Larvae & DW vs DW & ACV vs DW & Avoidance test & Confirmatory test \\
\hline 1st set & 0 & 0.34 & 0.11 & -0.08 \\
2nd set & 0.01 & 0.26 & 0.14 & -0.07 \\
3rd set & 0 & 0.16 & 0.19 & -0.03 \\
\hline
\end{tabular}

\section{Statistical analysis}

Students $t$-test was performed to compare the mean ORI of control vs NaF-treated flies, and $P<0.05$ was considered as statistically significant.

\section{Results}

The ORI of $Z$. indianus larvae towards IAA and ACV is shown in Table 1. The larvae were not found to be attracted towards IAA. However, they showed attraction towards ACV. $10^{-2}$ was the favored concentration. So, $10^{-2}$ concentration of ACV was taken for further olfactory assay.

Sublethal concentration of $\mathrm{NaF}$ for $Z$. indianus was found to be $0.8 \mathrm{ppm}$. This concentration was used for performing olfactory assay because flies were found to survive and reproduce in this concentration (Table 2). On the other hand, $1.0 \mathrm{ppm}$ and $1.5 \mathrm{ppm} \mathrm{NaF}$ concentrations were found to be lethal for the flies as at this concentration the flies were unable to reproduce and grow in number (Tables 3 and 4).

Larvae reared on normal cornmeal medium were taken as control and were assessed for their learning and memory ability by performing olfactory assay with $10^{-2}$ concentration of ACV (Table 5). Z indianus larvae reared on $0.8 \mathrm{ppm}$ concentration of $\mathrm{NaF}$ were assessed for their learning and memory ability by performing olfactory assay with $10^{-2}$ concentration of apple cider vinegar (Table 6). A statistically significant difference was found in the means of ORI of normal vs NaF-treated larvae during the confirmatory test $(t, 4.3 ; \mathrm{df}=4 ; P<0.05)$ (Table 7).

\section{Discussion}

Olfactory assay of the larvae of native $Z$. indianus has been conducted for the first time in the present study. Khurana and Siddiqui (2013) studied the response of 3rd instar Drosophila larvae towards 53 odorants. Such

Table 6 Olfactory Response Index (ORI) for NaF-treated Zaprionus indianus larvae

\begin{tabular}{lllll}
\hline Larvae & DW versus DW & ACV versus DW & $\begin{array}{l}\text { Avoidance } \\
\text { test }\end{array}$ & $\begin{array}{l}\text { Confirmatory } \\
\text { test }\end{array}$ \\
\hline 1st set & 0.02 & 0.10 & 0.13 & 0.02 \\
2nd set & 0 & 0.21 & 0.17 & 0.07 \\
3rd set & 0.01 & 0.13 & 0.14 & 0.01 \\
\hline
\end{tabular}


Table 7 Comparison of Olfactory Response Index of 2nd instar larvae of normal and fluoride-treated Zaprionus indianus

\begin{tabular}{lllll}
\hline & Control (normal) & Mean \pm SE & NaF treated & Mean \pm SE \\
\hline Control & $0,0.01,0$ & $0.00 \pm 0.003$ & $0.02,0.12,0.03$ & $0.05 \pm 0.03$ \\
Experimental & $0.06,0.26,0.16$ & $0.16 \pm 0.05$ & $0.19,0.34,0.13$ & $0.22 \pm 0.06$ \\
Avoidance & $0.11,0.14,0.23$ & $0.33 \pm 0.03$ & $0.09,0.10,-0.17$ & $0.01 \pm 0.08$ \\
Confirmatory & $-0.08,-0.07,-0.03$ & $-0.06 \pm 0.01^{*}$ & $0.02,0,0.01$ & $0.01 \pm 0.005^{*}$ \\
\hline
\end{tabular}

*Significant difference at $P<0.05$

elaborate studies on response profile of Drosophila larvae were very valuable while performing olfactory assay. Tabassum, Kumari, Singh, and Yasmin (2017) studied a comparative account of the olfactory behavior of pureline Drosophila melanogaster (inbred up to 10 generations) and $\mathrm{CsBz}$ with that of native Drosophila melanogaster by using iso-amyl acetate odourant.

Zaprionus indianus larvae did not show appreciable response towards iso-amyl acetate. So, based on experiments done by Joshi et al. (2014) at Pennsylvania, ACV was used as attractant. Based on the ORI values obtained, it was observed that $Z$. indianus larvae showed maximum attraction at $10^{-2}$ concentration apple cider vinegar.

In the experiment, it was found that 2nd instar larvae of Zaprionus indianus showed abnormalities on treatment with $\mathrm{NaF}$. At concentration of $\mathrm{NaF}$, more than 0.8 ppm (i.e., $1.0 \mathrm{ppm}$ and $1.5 \mathrm{ppm}) Z$. indianus flies did not lay eggs, and flies died in a few days. Due to the effect of fluoride, the learning and memory ability of Zaprionus larvae was hampered, which became evident with the ORI results obtained (positive value of confirmatory test), as opposed to the ORI results of normal larvae (not exposed to $\mathrm{NaF}$ ), where ORI value was negative during confirmatory test. The abnormalities displayed by NaF-treated Zaprionus indianus larvae can be said to be because of $\mathrm{NaF}$ reacting with the brain of the larvae. Fluoride is a known neurotoxin (Spittle, 2011). F toxicity may also result in low IQ children (Yasmin et al. 2013).

Though, the killing action of fluoride can be very helpful in insecticides (Metcalf, 1966), the aspect of fluoride affecting the nervous system cannot be dealt leniently (Grandjean and Landrigan, 2014). Z. indianus has been considered as a pest in many countries such as Veracruz in Mexico (Lasa and Tadeo, 2015). But the fact that it is found in the orchards indicates that it may be helping in the process of pollination (Landolt et al., 2012). This makes the fly a significant component of the natural ecosystem. If all such flies and other insects are treated with pesticides containing fluoride, it can lead to their death or reduced efficiency in carrying out pollination. In either case, the whole system of symbiotic association between trees and the insects will be disrupted. This will ultimately lead to reduced productivity of the trees.

\section{Conclusions}

The study showed that NaF-treated larvae suffered some neurological disorder that affected their learning and memory ability. Pesticides containing fluoride can cause death of non-target insect populations or can reduce their efficiency in carrying out pollination by affecting their learning and memory aspects.

\section{Abbreviations \\ NaF: Sodium fluoride; IAA: Iso-amyl acetate; ACV: Apple cider vinegar; ORI: Olfactory Response Index}

\section{Acknowledgements}

We are grateful to Dr. Sister Maria Rashmi A. C., Principal, Patna Women's College for providing us all the facilities for carrying out the study. We are also grateful to Dr. M C Arunan of HBCSE, Mumbai, and CUBE mailing group for their valuable suggestions. We are also thankful to the Research Committee for providing the facilities.

\section{Authors' contributions}

Equally contributed. The author(s) read and approved the final manuscript.

\section{Funding}

NA

\section{Availability of data and materials}

NA

\section{Ethics approval and consent to participate} NA

\section{Consent for publication}

NA

\section{Competing interests}

The authors declare that they have no conflict of interest.

Received: 17 June 2019 Accepted: 20 May 2020

Published online: 27 May 2020

\section{References}

Frye, M. A., \& Dickinson, M. H. (2004). Motor output reflects the linear superposition of visual and olfactory inputs in Drosophila. Journal of Experimental Biology, 207, 123-131. https://doi.org/10.1242/jeb.00725.

Gailey, D. A., Lacaillade, R. C., \& Hall, J. C. (1986). Chemosensory elements of courtship in normal and mutant, olfaction-deficient. Drosophila melanogaster. Behavioural Genetics, 16(3), 375-405. https://doi.org/10.1007/BF01071319.

Grandjean, P., \& Landrigan, P. (2014). Neurobehvioural effects of developmental toxicity. Lancet Neurology, 13(3), 330-338. https://doi.org/10.1016/S14744422(13)70278-3.

Gupta, J. P. (1970). Description of a new species of Phorticella and Zaprionus (Drosophilidae) from India. Proceeding Indian National Science Academy, 36, 62-70.

Jeibmann, A., \& Paulus, W. (2009). Drosophila melanogaster as a model organism for brain diseases. International Journal of Molecular Sciences, 10(2), 407-440. https://doi.org/10.3390/ijms10020407. 
Joshi, N. K., Biddinger, D. J., Demchak, K., \& Deppen, A. (2014). First report of Zaprionus indianus in Pennsylvania. Journal of Insect Science, 14, 259-263. https://doi.org/10.1093/jisesa/ieu121.

Keene, A. C. \& Waddell, S. (2007). Drosophila olfactory memory: single genes to complex neural circuits. Nature Reviews Neuroscience, 8(5), 341-354. https:// doi.org/10.1038/nrn2098.

Khurana, S., \& Siddiqui, O. (2013). Olfactory responses of Drosophila larvae. Chemical senses, 38, 315-323. https://doi.org/10.1093/chemse/bjs144.

Kofman, O., Berger, A., Massarwa, A., Friedman, A., \& Jaffar, A. A. (2006). Motor inhibition and learning impairments in school-aged children following exposure to organophosphate pesticides in infancy. Pediatric Research, 60 88-92. https://doi.org/10.1203/01.pdr.0000219467.47013.35.

Landolt, P. J., Adams, T., Davis, T. S., \& Rogg, H. (2012). Spotted wing Drosophila, Drosophila suzukii (Diptera: Drosophilidae), trapped with combinations of wines and vinegars. Florida Entomologist, 95(2), 326-332. https://doi.org/10. 1653/024.095.0213

Lasa, R., \& Tadeo, E. (2015). Invasive drosophilid pests Drosophila suzukii and Zaprionus indianus (Diptera:Drosophilidae) in Veracruz, Mexico. Florida Entomologist, 98(3), 987-988. https://doi.org/10.1653/024.098.0332.

London, L., Beseler, C., Bouchard, M. F., Bellinger, D. C., Colosio, C., Grandjean, P., \& Harari, R. (2012). Neurobehavioral and neurodevelopmental effects of pesticide exposures. Neurotoxicology, 33, 887-896. Stallones, L. https://doi. org/10.1016/j.neuro.2012.01.004

Metcalf, R. L. (1966). Fluorine-containing insecticides. In: Smith F.A. (eds) Pharmacology of fluorides. Handbook of Experimental Pharmacology, 20, 355386.

Quinn, W. G., Harris, W. A., \& Benzer, S. (1974). Conditioned behavior in Drosophila melanogaster. Proceedings of National Academy of Sciences USA, 71, 708-712. https://doi.org/10.1073/pnas.71.3.708.

Rubin, G. M., Yandell, M. D., Wortman, J. R., Gabor Miklos, G. L., Nelson, C. R. Hariharan, I. K., ... Lewis, S. (2000). Comparative genomics of the eukaryotes. Science, 287, 2204-2215.

Scherer, S., Stocker, R. F., \& Bertram Gerber, B. (2003). Olfactory learning in individually assayed Drosophila larvae. Learning memory, 10(3), 217-225. https://doi.org/10.1101//m.57903.

Schneiderman, A. M., \& Trimarchi, J. R. (1995). Different neural pathways coordinate Drosophila flight initiations evoked by visual and olfactory stimuli. Journal of Experimental Biology, 198, 1099-1104.

Shaver, S. A., Varnam, C. J., Hilliker, A. J., \& Sokolowski, M. B. (1998). The foraging gene affects adult but not larval olfactory-related behavior in Drosophila melanogaster. Behavioural Brain Research, 95(1), 23-29. https://doi.org/10. 1016/50166-4328(97)00206-4.

Spittle, B. (2011). Neurotoxic effects of fluoride [editorial]. Fluoride, 44, 117-124. Tabassum, F., Kumari, N., Singh, R., \& Yasmin, S. (2017). Olfactory behavior and learning in native vs lab-bred Drosophila melanogaster. IRIS Journal for Young Scientists, 7, 7-13.

Tully, T., \& Quinn, W. G. (1985). Classical conditioning and retention in normal and mutant Drosophila melanogaster. Journal of Comparative Physiology, 157, 263-277. https://doi.org/10.1007/BF01350033

Yasmin, S., Ranjan, S., Hilaluddin, \& D'Souza, D. (2013). Effect of excess fluoride ingestion on human thyroid function in Gaya region, Bihar, India. Toxicological \& Environmental Chemistry, 95(7), 1235-1243. https://doi.org/10. 1080/02772248.2013.847619.

\section{Publisher's Note}

Springer Nature remains neutral with regard to jurisdictional claims in published maps and institutional affiliations.

\section{Submit your manuscript to a SpringerOpen ${ }^{\circ}$ journal and benefit from:}

- Convenient online submission

- Rigorous peer review

- Open access: articles freely available online

- High visibility within the field

- Retaining the copyright to your article

Submit your next manuscript at $\boldsymbol{\nabla}$ springeropen.com 